\title{
PENERAPAN PROBLEM BASED LEARNING MELALUI SIMULASI PHET UNTUK MENINGKATKAN PEMAHAMAN KONSEP SISWA PADA MATERI ENERGI MEKANIK DI SMA
}

\author{
Fajri Yanti ${ }^{1}$, Muhammad Daud ${ }^{2}$, Syarifah Rita Zahara ${ }^{2}$ \\ ${ }^{1}$ Mahasiswa dan ${ }^{2}$ Dosen Program Studi Pendidikan Fisika, FKIP Unimal, Aceh Utara \\ Korespondensi:fajriyanti81@gmail.com
}

\begin{abstract}
Abstrak: Tujuan penelitian ini untuk mengetahui bagaimana peningkatan pemahaman konsep siswa pada materi energi mekanik melalui penerapan model pembelajaran Problem Based Learning (PBL) dan simulasi PhET di SMA Negeri 3 Bireuen. Penelitian ini menggunakan kuasi eksperimen dengan desain penelitian Nonequivalent Control Group Design dengan jumlah responden sebanyak 52 orang. Instrumen pengumpulan data pemahaman konsep adalah tes. Data dianalisis dengan statistik parametris, yaitu uji-t dengan teknik independent sample t-test. Berdasarkan hasil penelitian dan pembahasan, dapat disimpulkan bahwa terdapat pengaruh model pembelajaran Problem Based Learning (PBL) melalui simulasi PhET terhadap peningkatan pemahaman konsep siswa pada materi energi mekanik di kelas XI SMA Negeri 3 Bireuen. Dan dapat dilihat dari hasil uji independent sample t-test dengan nilai Sig (2-tailed) yaitu 0,002, artinya nilai Sig (2-tailed) $0,002<0,05$, maka sebagaimana dasar pengambilan keputusan dalam uji independent sample t-test dapat disimpulkan bahwa Ho ditolak dan Ha diterima. Dengan rata-rata postest kelas eksperimen diatas KKM (Kriteria Ketuntasan Minimal).
\end{abstract}

Kata Kunci: Problem Based Learning (PBL), Simulasi Phet, Pemahaman Konsep Siswa

\section{APPLICATION OF PROBLEM BASED LEARNING THROUGH PHET SIMULATION TO INCREASE STUDENT CONCEPT UNDERSTANDING ON MECHANICAL ENERGY MATERIALS IN HIGH SCHOOL}

\begin{abstract}
Abstrac: The purpose of this study was to find out how to increase students' understanding of concepts in mechanical energy material through the application of Problem Based Learning (PBL) learning models and PhET simulations in SMA N 3 Bireuen. This study used a quasiexperimental research design with Nonequivalent Control Group Design with 52 respondents. The instrument for understanding data collection concepts is a test. Data were analyzed with parametric statistics, namely t-test with independent sample t-test techniques. Based on the results of research and discussion, it can be concluded that there is an influence of the Problem Based Learning (PBL) learning model through PhET simulations on improving students' understanding of the concept of mechanical energy in class XI of SMA Negeri 3 Bireuen. And it can be seen from the results of the independent sample t-test with the Sig (2-tailed) value that is 0.002, meaning that the Sig (2-tailed) value is $0.002<0.05$, then as the basis for decision making in the independent sample t-test can be concluded that Ho was rejected and Ha was accepted. With an average post-grade experimental above KKM (Minimum completeness criteria).
\end{abstract}

Keywords: Problem Based Learning (PBL), Phet Simulations, Students' Understanding Of Concepts 


\section{PENDAHULUAN}

Mata pelajaran fisika adalah salah satu unsur IPA yang memiliki peranan penting dalam proses perkembangan dan kemajuan IPTEK. Fisika merupakan pengetahuan yang disusun berdasarkan fakta, fenomena-fenomena alam, hasil pemikiran, dan hasil eksperimen. Perkembangan Ilmu Pengetahuan dan Teknologi (IPTEK) mempengaruhi hampir seluruh kehidupan manusia. Untuk dapat menguasai ilmu pengetahuan dan teknologi, maka kualitas sumber daya manusia harus ditingkatkan melalui peningkatan mutu pembelajaran disekolah. Guru sebagai salah satu komponen dalam proses pembelajaran harus terampil dalam menggunakan model dan media pembelajaran yang tepat. Tanpa penggunaan model dan media pembelajaran yang jelas, proses pembelajaran menjadi tidak terarah dan tidak menghasilkan hasil yang optimal (Suranti, 2016).

Dalam proses pembelajaran fisika, pemahaman siswa sangat dipengaruhi oleh kualitas metode pembelajaran yang digunakan oleh guru, karena kualitas suatu metode pembelajaran merupakan salah satu faktor untuk menentukan hasil belajar siswa. Selain itu, yang paling penting dalam proses pembelajaran ilmu fisika adalah memahami konsep, khususnya pada materi energi mekanik. Oleh karena itu, guru diharapkan mampu menerapkan konsep pada materi energi mekanik agar siswa dapat memahami konsep energi mekanik dengan jelas (Agustina, 2016). Banyak hal yang dapat ditempuh untuk mencapai tujuan pembelajaran seperti menciptakan suasana belajar siswa yang aktif, inovatif, kreatif dan menyenangkan agar mereka bergairah dan berkembang sepenuhnya selama proses pembelajaran (Kono dan Mamu, 2016).

Berdasarkan hasil observasi penulis di SMA Negeri 3 Bireuen, diketahui bahwa sebagian besar siswa mengalami kesulitan dalam menggunakan hukum kekekalan energi. Menurut siswa energi potensial elastis hanya dimiliki oleh benda yang diregangkan saja, sedangkan benda yang ditekan tidak. dan siswa juga belum mampu membedakan antara energi potensial dengan energi kinetik ketika di kaitkan dalam kehidupan nyata. Hal ini disebabkan oleh proses pembelajaran fisika di kelas XI selama ini dengan menggunakan model Problem Based Learning (PBL) dan diskusi masih kurang menyenangkan bagi siswa. Ketika guru menggunakan model Problem Based Learning (PBL) maka hanya siswa yang aktif saja yang paham terhadap konsep yang diajarkan, sementara guru selama ini lebih banyak menunggu hasil diskusi yang siswa dapatkan tanpa menyediakan fasilitas yang memadai. Sehingga menyebabkan siswa kurang dalam memahami konsep pada pembelajaran fisika khususnya pada materi energi mekanik. Agar tujuan pembelajaran fisika di SMA Negeri 3 Bireuen dapat dicapai maka perlu adanya inovasi dalam proses pembelajaran fisika di kelas XI. Inovasi tersebut dapat berupa model pembelajaran dan juga media simulasi yang dapat meningkatkan pemahaman konsep siswa kelas XI khususnya pada materi energi mekanik.

Salah satu upaya untuk meningkatkan pemahaman konsep siswa kelas XI pada materi energi mekanik adalah dengan menerapkan model pembelajaran Problem Based Learning $(P B L)$ melalui simulasi PhET. Problem Based Learning (PBL) adalah model pembelajaran yang mendorong siswa untuk belajar dan bekerjasama dalam kelompok untuk mencari penyelesaian masalah-masalah di dunia nyata (Restiono, 2013). Physics Education Tecnology atau PhET merupakan sebuah aplikasi yang berisi berbagai simulasi yang berguna untuk mengajar dan belajar fisika yang dikembangkan oleh Universitas Colorado (Sugiarti, 2013).

Berdasarkan penelitian Dwi (2013) yang bertujuan untuk menguji perbedaan pemahaman konsep dan kemampuan pemecahan masalah antara siswa yang diajarkan dengan menggunakan strategi $P B L$ berbasis $I C T$ dan siswa yang dibelajarkan dengan strategi $P B L$. Hasil analisis data menunjukkan: (1) terdapat perbedaan pemahaman konsep yang signifikan antara siswa yang dibelajarkan dengan menggunakan strategi $P B L$ berbasis $I C T$ dan strategi $P B L$; (2) terdapat perbedaan kemampuan pemecahan masalah yang signifikan antara siswa 
yang dibelajarkan dengan menggunakan strategi $P B L$ berbasis $I C T$ dan strategi $P B L$. Rahayu (2017) yaitu Penelitian yang bertujuan untuk meningkatkan pemahaman konsep siswa setelah dilaksanakan pembelajaran menggunakan pendekatan saintifik dengan media simulasi PhET pada materi gelombang. Berdasarkan hasil penelitian yang telah dilakukan dapat disimpulkan bahwa penerapan pendekatan saintifik dengan media simulasi PhET dapat meningkatkan pemahaman konsep siswa.

\section{METODE PENELITIAN}

Desain yang digunakan dalam penelitian ini adalah quasi experimental design dan menggunakan model nonequivalent control group design. Sebelum diberi treatment, baik kelompok eksperimen dan kelompok kontrol diberi test yaitu pretest, dengan maksud untuk mengetahui keadaan kelompok sebelum treatment pada pokok bahasanenergi kinetik, energi mekanik dan energi potensial, dengan jumlah responden sebanyak 52 orang. Instrumen pengumpulan data pemahaman konsep adalah tes. Data dianalisis dengan statistik parametris, yaitu uji-t dengan teknik independent sample t-test. Penelitian ini dilakukan dalam dua kali pertemuan.

Gambar

3.1

berikut merupakan gambar quasi experimental design model Nonequivalent Control Group D esign (Setyanto, 2006).

$$
\begin{array}{|c|}
\frac{\mathbf{0}_{\mathbf{1}} X \mathbf{0}_{\mathbf{2}}}{\mathbf{0}_{\mathbf{3}} \mathbf{0}_{\mathbf{4}}} \\
\text { Gambar 1 Nonequivalent Control Group Design }
\end{array}
$$

Keterangan :

$0_{1}=$ Kelompok eksperimen sebelum diberi treatment

$0_{2}=$ Kelompok ekperimen setelah diberi treatment

$0_{3}=$ Kelompok kontrol sebelum ada treatment

$0_{4}=$ Kelompok kontrol yang tidak diberi treatment (PBL tanpa PhET)

$X=$ Treatment (penggunaan media simulasi PhET)

Populasi dalam penelitian yang dilakukan di SMA Negeri 3 Bireuen adalah seluruh siswa kelas XI. Tahun ajaran 2019/2020 kelas XI terdiri dari tiga kelas yaitu kelas XI IPA-1, XI IPA-2 dan XI IPA-3 dengan total keseluruhan siswa kelas XI yaitu 78 siswa. Dalam penelitian ini teknik sampling yang digunakan yaitu nonprobability sampling dengan teknik purposive sampling. Adapun Sampel yang dipilih yaitu terdiri dari dua kelas yaitu kelas XI IPA-1 sebagai kelas eksperimen dan kelas X IPA-2 sebagai kelas kontrol dengan jumlah peserta didik masing-masing 27 siswa. Laki-laki terdiri dari 5 orang dan perempuan terdiri dari 22 orang pada masing-masing kelas.

\section{HASIL DAN PEMBAHASAN \\ Hasil}

Hasil penelitian ini diperoleh dengan perlakuan pretest dan postest yang berbentuk soal pilihan ganda sebanyak 35 soal untuk mengukur penguasaan konsep. Penelitian ini bertujuan untuk menganalisis penguasaan konsep peserta didik dengan menerapkan model Problem Based Learning (PBL) yang dibantu dengan media simulasi PhET terhadap kelas eksperimen yaitu kelas XI IPA-1 dan pembelajaran Problem Based Learning (PBL) tanpa simulasi (PhET) terhadap kelas kontrol yaitu kelas XI IPA-2 yang terdiri dari 27 siswa, laki- 
laki terdiri dari 5 orang siswa dan perempuan terdiri dari 22 orang siswa pada masing-masing kelas di SMA Negeri 3 Bireuen pada materi energi mekanik.

Berdasarkan hasil belajar Pretest dapat disimpulkan bahwa dari 27 peserta didik pada masing-masing kelas, yang di ikut sertakan dalam pretest diperoleh nilai rata-rata pretest kelas kontrol yaitu 59,00 sedangkan nilai rata-rata pretest kelas eksperimen yaitu 60,85. Nilai rata-rata pre test baik di kelas eksperimen maupun kelas kontrol masih di bawah KKM. Hal ini dikarenakan kedua kelas belum mendapatkan media belajar yang tepat. Secara umum dapat disimpulkan bahwa perolehan pemahaman konsep siswa pada pre test antara kedua kelas relatif sama. Selanjutnya untuk menguji kenormalan dan kesamaan antara kedua kelas tersebut, maka dilakukan pengujian normalitas, homogenitas, dan uji independen sample $t$ test yaitu uji untuk membandingkan dua sampel yang tidak saling berpasangan antara ratarata nilai post tes.

Output SPSS hasil uji normalitas diketahui nilai signifikansi uji shapiro wilk untuk nilai pre test eksperimen (PBL menggunakan PhET) yaitu 0,200 $>0,05$, maka dapat disimpulkan bahwa uji shapiro wilk untuk nilai pre test kelas eksperimen (PBL menggunakan $\mathrm{PhET}$ ) adalah data populasi berdistribusi normal. Nilai signifikansi uji shapiro wilk untuk nilai Pos Test eksperimen (PBL menggunakan PhET) yaitu 0,310 $>0,05$, maka dapat disimpulkan bahwa uji shapiro wilk untuk nilai Pos Test kelas eksperimen (PBL menggunakan PhET) adalah data populasi berdistribusi normal. Nilai signifikansi uji shapiro wilkuntuk nilai Pre Testkontrol (PBL tanpa PhET) yaitu 0,241>0,05, maka dapat disimpulkan bahwa uji shapiro wilk untuk nilai Pre Test kelas kontrol (PBL menggunakan PhET) adalah data populasi berdistribusi normal. Nilai signifikansi uji shapiro wilk untuk nilai Pos Test kontrol (PBL tanpa PhET) yaitu 0,091>0,05, maka dapat disimpulkan bahwa uji shapiro wilk untuk nilai Pos Test kelas kontrol (PBL menggunakan PhET) adalah data populasi berdistribusi normal. Output SPSS hasil uji homogenitas diketahui nilai Signifikansi (Sig) adalah sebesar $0.460>0,05$, sehingga dapat disimpulikan bahwa varians kelas adalah sama atau homogen.

Output SPSS Statistik Grup dapat disimpulkan bahwa adanya perbedaan nilai rata-rata antara kelas eksperimen yang diterapkan model pembelajaran Problem Based Learning (PBL) melalui simulasi PhET dengan kelas kontrol Problem Based Learning (PBL) tanpa PhET dengan nilai nilai rata-ratayaitu 62,00 dan 60,19. Output SPSS Uji Sampel Independen diketahui nilai signifikan tes levene untuk Kesetaraan Varian adalah sebesar 0,46>0,05 maka dapat diartikan bahwa varians data antara kelas eksperimen dengan kelas kontrol adalah homogen atau sama. Sehingga penafsiran tabel output Uji Sampel Independendi atas berpedoman pada nilai yang terdapat dalam tabel "Varians yang sama diasumsikan". Berdasarkan tabel output "Uji Sampel Independen" pada bagian "Varians yang sama diasumsikan"diketahui nilai Sig (2-tailed) sebesar $0.002<0.05$, maka sebagaimana dasar pengambilan keputusan dalam Uji Sampel Independen dapat disimpulkan bahwa Ho ditolak dan Ha diterima. Dengan demikian dapat disimpulkan bahwa adanya pengaruh model pembelajaran Problem Based Learning (PBL) melalui simulasi PhET terhadap peningkatan pemahaman konsep siswa pada materi energi mekanik di kelas XI SMA Negeri 3 Bireuen.

\section{Pembahasan}

Berdasarkan hasil penelitian, pengukuran pemahaman konsep siswa dalam penelitian ini dilakukan setelah memberi perlakuan pada kelas eksperimen. Perlakuan pada kelas eksperimen yaitu dengan menerapkan model pembelajaran Problem Based Learning (PBL) melalui simulasi PhET pada materi energi mekanik. Dari hasil postest pemahaman konsep diperoleh hasil rata-rata kelas eksperimen sebesar 62,00. Sedangkan kelas kontrol yaitu 60,19. Skor tertinggi dan terendah pada kelas eksperimen adalah 66 dan 56. Jadi berdasarkan hasil uji independent sample t-testdapat disimpulkan bahwa adanya pengaruh model 
pembelajaran Problem Based Learning (PBL) melalui simulasi PhET terhadap peningkatan pemahaman konsep siswa pada materi energi mekanik di kelas XI SMA Negeri 3 Bireuen, dengan nilai Sig (2-tailed) yaitu 0,002, artinya nilai Sig (2-tailed) 0,002<0,05, maka sebagaimana dasar pengambilan keputusan dalam uji independent sample t-test dapat disimpulkan bahwa Ho ditolak dan Ha diterima. Dengan rata-rata postestkelas eksperimen di atas KKM (Kriteria Ketuntasan Minimal).

Hasil penelitian tersebut sesuai dengan beberapa penelitian lain seperti. 1)model pembelajaran berbasis masalah berbantuan media PhET berpengaruh terhadap hasil belajar fisika siswa kelas X SMA N 1 Gunungsari tahun pelajaran 2015/2016 (Wahyudi, 2016). 2) Implementasi simulasi PhET dan KIT sederhana untuk mengajarkan keterampilan psikomotor siswa pada pokok bahasan alat optik dapat menuntaskan hasil belajar psimotor siswa. 3). Penerapan pembelajaran fisika menggunakan media PhET Simulations pada materi cahaya di kelas VIII SMP Negeri 7 Bojonegoro berlangsung dengan sangat baik dan berpengaruh positif terhadap hasil belajar siswa serta respon siswa sangat baik (Mubarrok, 2014), serta penerapan media simulasi menggunakan PhET dapat meningkatkan hasil belajar Fisika sebesar $\mathrm{N}=0,4$ dalam kategori sedang pada siswa kelas $\mathrm{X}$ SMA Muhammadiyah Limbung (Ekawati, 2014).

Faktor pertama yang mempengaruhi lebih tingginya pemahaman konsep siswa pada kelas eksperimen terletak di awal pembelajaran. Masalah yang dimunculkan dari simulasi PhET, Animasi lebih mempermudah siswa dalam memahami sesuatu dari pada yang lain. Hal ini sesuai dengan pernyataan Sukiyasa (2013) media animasi lebih tinggi dari hasil belajar dan motivasi belajar siswa yang diajarkan dengan media powerpoint. Didukung juga oleh pernyataan Komaro (2014) multimedia interaktif mempunyai pengaruh yang signifikan terhadap hasil belajar siswa pada kompetensi perbaikan differential. Beberapa peneliti seperti Hutagaol (2013); Haji (2012); Putra (2017), mengungkapkan bahwa pembelajaran kontekstual adalah konsep belajar dimana guru menghadirkan dunia nyata ke dalam kelas dan mendorong siswa untuk membuat hubungan antara pengetahuan yang dimilikinya dengan penerapannya dalam kehidupan sehari-hari.

Faktor kedua yang mempengaruhi lebih tingginya pemahaman konsep siswa pada kelas eksperimen terletak pada kegiatan inti sebagai akibat dari faktor pertama. Mereka lebih termotivasi dan lebih berkonsentrasi dalam menyelesaikan tugas, sehingga berpengaruh pada setiap tahapan pembelajaran berikutnya. Hal tersebut sesuai dengan pendapat putri, (2017), bahwa orang yang mempunyai motivasi yang tinggi dalam belajar maka akan menimbulkan minat yang besar dalam mengerjakan tugas, membangun sikap dan kebiasaan belajar yang sehat melalui penyusunan jadwal belajar dan melaksanakannya dengan tekun. Faktor ketiga yang mempengaruhi lebih tingginya pemahaman konsep siswa pada kelas eksperimen terletak pada kegiatan penutup berupa tes pemahaman konsep fisika di setiap akhir pembelajaran. Guru mendidik dan melatih siswa mengerjakan tes pemahaman konsep agar memiliki pemahaman konsep yang lebih baik.

Dalam mengoptimalkan pemanfaatan model pembelajaran Problem Based Learning (PBL) melalui simulasi PhET hendaknya perlu diperhatikan beberapa hal, yaitu sebagai berikut:

(1) Kemampuan awal hendaknya diperhatikan dengan baik agar pelaksanaan pembelajaran dapat mencapai hasil yang diharapkan;

(2) Dalam menerapkan model pembelajaran Problem Based Learning (PBL) melalui simulasi PhET hendaknya mengatur sebaik mungkin alokasi waktu yang tersedia, sehingga tiap fase pembelajaran dapat berlangsung secara optimal;

(3) Program simulasi PhET yang dipakai dalam pembelajaran hendaknya adalah Program PhET yang menggunakan bahasa Indonesia sebagai bahasa pengantar, agar siswa tidak kebingungan ketika mengoperasikannya. 


\section{PENUTUP}

Berdasarkan hasil penelitian dan pembahasan, dapat disimpulkan bahwa terdapat pengaruh model pembelajaran Problem Based Learning(PBL) melalui simulasi PhET terhadap peningkatan pemahaman konsep siswa pada materi energi mekanik di kelas XI SMA Negeri 3 Bireuen. Dan dapat dilihat dari hasil uji independent sample t-test dengan nilai Sig (2-tailed) yaitu 0,002, artinya nilai Sig (2-tailed) 0,002<0,05, maka sebagaimana dasar pengambilan keputusan dalam uji independent sample t-test dapat disimpulkan bahwa Ho ditolak dan Ha diterima. Dengan rata-rata post test kelas eksperimendiatas KKM (Kriteria Ketuntasan Minimal).

\section{DAFTAR PUSTAKA}

Agustina. (2016). Upaya Meningkatkan Kemampuan Pemahaman Konsep dan Pemecahan Masalah Matematika Siswa SMP Negeri 4 Sipirok Kelas VII Melalui Pendekatan Matematika Realistik (PMR). Jurnal Eksakta Volume 1.

Dwi. (2013). Pengaruh Strategi Problem Based Learning. Jurnal Pendidikan Fisika Indonesia (Indonesian Journal of Physics Education), 9(1).

Ekawati. (2014). Penerapan Media Simulasi Menggunakan PhET (Physics Education and Technology) Terhadap Hasil Belajar Fisika Peserta Didik Kelas X SMA Muhammadiyah Limbung. Jurnal Pendidikan Fisika Universitas Muhammadiyah Makassar. 3(1).

Hutagaol Kartini. (2013). Pembelajaran Kontekstual untuk Meningkatkan Kemampuan Representasi Matematis Siswa Sekolah Menengah Pertama. Jurnal Ilmiah Program Studi Matematika STKIP Siliwangi Bandung, 2(1).

Kono dan Mamu. (2016). Pengaruh Model Problem Based Learning (PBL) Terhadap Pemahaman Konsep Biologi dan Keterampilan Berpikir Kritis Siswa Tentang Ekosistem dan Lingkungan di Kelas X SMA Negeri 1 Sigi. jurnal Sains dan Teknologi, 5(4): $28-38$.

Mubarrok. (2014). Penerapan Pembelajaran Fisika Pada Materi Cahaya Dengan Media Phet Simulations Untuk Meningkatkan Pemahaman Konsep Siswa di SMP. Jurnal Inovasi Pendidikan Fisika (JIPF). 3.

Putra Fredi Ganda. (2017). Eksperimentasi Pendekatan Kontekstual Berbantuan Hands on Activity (HoA) Terhadap Kemampuan Pemecahan Masalah Matematik. Al-Jabar: Jurnal Pendidikan Matematika. 8(1)

Rahayu. (2017). Penerapan Pendekatan Saintifik Dengan Media Penerapan Pendekatan Saintifik Dengan Media Simulasi PhET Pada Materi Gelombang Untuk Meningkatkan Pemahaman Konsep Siswa SMP. Program Studi Pendidikan Sains Fmipa Universitas.

Restiono Awal. (2013). Penerapan Model Problem Based Learning Untuk Mengembangkan Aktivitas Berkarakter dan Meningkatkan Pemahaman Konsep Siswa Kelas XI. .Jurnal Penelitian Pendidikan, Universitas Negeri Semarang.

Setyanto Eko. (2006). Memperkenalkan Kembali Metode Eksperimen dalam Kajian Komunikasi. Jurnal Ilmu Komunikasi. 3(1). 
Suranti. (2016). Pengaruh Model Project Based Learning Berbantuan Media Visual Terhadap Penguasaan Konsep Peserta Didik Pada Materi Alat-Alat Optik. Jurnal pendidikan fisika dan teknologi, 2(2).

Sugiarti. (2013). Peran Sain Dalam Abad 21. jurnal. Prosiding Universitas PGRI Palembang.

Sukiyasa Kadek dan Sukoco. (2013). Pengaruh Media Animasi Terhadap Hasil Belajar dan Motivasi Belajar Siswa Materi Sistem Kelistrikan Otomotif. Jurnal Pendidikan Vokasi, 3(1). 